\title{
Enhancing Usability of E-Leaming Platform: A Case Study of Khan Academy
}

\author{
* Maham Sheikh \\ ** Abdul Hafeez Muhammad (Corresponding Author) \\ *** Quadri Noorul hasan Naveed
}

\begin{abstract}

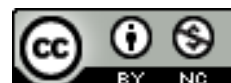

Human-Computer Interaction (HCI) is a subject that measures usability and evaluates the interface of a system, software, or product to see its efficiency, effectiveness, and user satisfaction. On the other hand, at the time, the pandemic spread of Coronavirus (Covid-19) having an immense impact on schools, universities, and other educational sectors. In this current unpredictable situation, the importance of online education is visible, therefore, the usability of e-learning platforms truly plays an essential role in our lives. This study is about to evaluate the usability of a very common e-learning portal i.e., Khan Academy by user testing and heuristic evaluation techniques. Effectiveness, efficiency, and satisfaction of Khan Academy were measured quantitatively, while usability issues were identified qualitatively through heuristic evaluation. The study result shows that Khan Academy suffers from certain usability problems which need to be addressed. The study also presents relevant recommendations which are scrutinized and approved by IT specialists and UI/UX designers. The study concluded that suggested amendments are important to consider enhancing the usability of different e-Learning portals generally and Khan Academy particularly.
\end{abstract}

Keywords: Usability, Usability Evaluation, Heuristic Evaluation, E-learning Usability, HumanComputer Interaction, System Usability Scale, Single Ease Questionnaire, Usability Metrics

\section{Introduction}

Designing an effective and useful system has always been a difficult task. E-learning applications are needed by learners for multiple purposes, for instance providing learning paths, research work, preparing lectures, and so on. Usability is a major concern in designing software, web interface, mobile applications, or hardware devices. The target of usability is not only to make the product usable but satisfactory. Usability Metrics contains the three most important matrices, which are Effectiveness, Efficient, and Satisfaction. A product is considered used if it achieves these parameters (Al-Badi et al., 2013). Usability is an intellectual term to study directly, it is usually alienated into the five attributes: Learnability, Efficiency, User retention over time, Error rate, and Satisfaction (AlDossari, 2017). Today, usability is be ing used around everywhere in every field of life. Usability links with the interface of any object, website, or application. The usability of products gains importance not only for the users of a system but also for manufacturing organizations. According to Jokela, the benefits for users are comprehensive and include increased productivity, improved quality of work, and enlarged user satisfaction. Manufacturers also gain profits significantly through a reduction of support and training costs. With the help of usability, the ratio of profit and loss could change. Many organization contacts graphic designers to improve the usability of their concerned applications to seek the attention of users. Hence, a product with good usability can enhance the income of an organization.

To make users completely focused on a particular system, the usability of the system should be at the acceptance level. Human-Computer Interaction (HCI) is a discipline that mainly focuses on a user's mental status and requirements. HCI has widely studied the psychology of users and so provided guide lines and strategies for a usable product. That could help designers to make a usable product for users. Therefore, usability plays a vital role while designing a good and user-friendly

\footnotetext{
* Department of CS, Bahria University Lahore Campus. Email: mahamsheikh.ncbae@gmail.com ** Department of Computer Science, Bahria University Lahore Campus. Email: ahafeez.bulc@bahria.edu.pk *** College of Computer Science, King Khalid University, Saudi Arabia. Email: qnaveed@kku.edu.sa
} 
system or product (Al-khalifa, 2010). HCI provides a valuable lesson that usability should be considered before the settlement of a prototype. There are methods for such initial focus and commitment. Developers usually ignore usability testing before designing and when applying after the design phase, it results quite expensive (Alshammari et al, 2015). Since 1998, usability told by ISO 9241-11 has been widely accepted internationally for applying usability. It is extensively referenced and use in research and has been named for a high level of understanding than before this version of usability (Alsumait, 2009).

Online studying often named MOOC (Massive Online Open Course) is becoming a new technology and system in today's world. In this very perspective, tools that provide learning materials to students and lecturers to lecturers are needed to be more updated and usable because many students (millions of students in a course) are using these tools. Khan Academy is an educational organization where multiple courses are available for students, teachers, and other learners. This website creates users' profiles and delivers lessons in the form of videos. It also provides exercise materials for practice for knowledge seekers. Khan Academy is used internationally, and many published book exercises are based on Khan Academy questions. Khan Academy is one of the emerging platforms of MOOC. It spreads learning analytics supports to its users. It is established in 2006 with nat ive English language. Also, Spanish, French, Portuguese, and Bengali are supported in this platform (Aslam et al., 2016). Khan Academy is famous for its unique capability of providing progress reports as feedback to its users (Instructors and students) without any cost (Lanzilotti, 2006).

The term Usability is known for methods to enhance the ease of use during the design process of a product (Thielsch et al., 2014). Usability is referred to as a quality object that is used to increase the ease of use of the product for the users through the design phase. During the evaluation process of the product, system usability is being tested mostly. In this phase, system usage carries out by users through the task(s) given by designers (Debevc, 2000). There are different factors includes efficiency, effectiveness, simplicity, learnability, memorability, consistency, and feedback that address usability (Ertürk \& Önaçan, 2016).

Objectives of the study

The main objective of the study is to enhance the Usability of Khan Academy's e-Learning Platform by using heuristic evaluation and user testing. To achieve it following are sub-objectives

- $\quad$ To measure the effectiveness, efficiency, and satisfaction of Khan Academy

- To identify the usability issues in the Khan academy using heuristic evaluation

Related Work

As technology is changing rapidly and becoming advance, it has also changed the human needs to get knowledge in more meaningful ways. For instance, through electronic media. E-learning systems are based on three criteria: "the e-learning is networked, it is provided to end-users through a basic internet connection, and it should be delivered to users in a way to modify the traditional educational paradigms". Often, it is seen that people mix the two terms usability and user experience that are opposite in their meanings. Usability is defined by ISO 9241-11 in 1998, which says to build a product that should be used that could help their end-users to achieve their intentional goals with effectiveness, efficiency, and satisfaction. Whereas User Experience is a term that means the responses of users after using a particular product, system, or any newly designed service (Gordillo et al., 2015).

One study shows that the usability of mobile learning applications is sighted (Granic, 2008), Mobile Learning is an extension of E-learning that makes users easy to approach learning analytics through more comfortable and smart devices. There are many mobile benefits included for elearning system, that are (a) no boundaries for location, one can contain knowledge anywhere, (b) helps learners to build their individual space of learning, (c) it can also help users for isolation of them. Authors in this systematic literature review (SLR) have widely explored mobile usability, also they proved that mobile usability has not been as much discussed in previous publications as it should be. Rather than the content of E-learning systems, their accessibility should be considered (Granic, 2008). In this research, the European Computer Driving License (ECDL) is considered as an e-learning platform; this platform divided the course into different modules. SUMI method has been selected in this research as an evaluation method. Results were shown positive overall from a usability perspective (Gordillo et al., 2015). When a system is not usable, a user may become frustrated and focus on the e-learning system rather than e-learning content. One study showed that 
two versions were compared and tested to study what impact of adaptive e-learning system has on usability instead of the non-adaptive e-learning system (Groth \& Haslwanter, 2015). Several user satisfaction techniques are used to interrogate users for interface designing. In a study the authors used SUS and UMUX-Lite questionnaire to target the UX design of the interface (Alshammari, 2016), The research was carried out on two closely re lated courses of Open Education and Coursera. Furthermore, an evaluation approach was used by authors; (Holzinger, 2005) evaluation based on Canole's 12 dimensions (Openness, Massiveness, Use of Multimedia, Collaboration, Communication, Learning Pathway, Quality assurance, Assessment, amount of reflection, Formal learning, Autonomy, Diversity) which shows the main properties of teaching methodologies. Research has also been carried out to evaluate LMSs (Jose, 2016), through different approaches, such as user motivation and engagement. Other researchers have derived a new scale to measure usability. They have used the approach System Usability Scale to measure the reliability of their scale (Korableva et al., 2019). This is an approved study that says (Katsanos et al., 2012). Questionnaires, Inquiry, and Focus groups are the most employed evaluation approaches, other than these, performance measure, Log files, Think-aloud protocol, and most of them are Heuristics Checklists, based on Nielson's standards. Usability is measured through an experiment (Freire et al., 2012), in which the SUS score is measured to ensure the interaction of teachers with MOOC platforms. It is observed during this experiment that SUS is not enough to measure these metrics.

A state-of-the-art further includes a few more types of research that contain the same interest by using different evaluation techniques for the LMSs.

Table 1: State-of-the-art for mapping different researches of usability evaluation of e-learning platforms.

\begin{tabular}{|c|c|c|}
\hline Ref \# & Platform & Evaluati on Method \\
\hline (Mkpojiogu et al., 2018) & Mobile learning platform for children & Questionnaires survey in SLR \\
\hline (Mtebe \& Kissaka, 2015) & Web-based E-Learning platforms & $\begin{array}{l}\text { Questionnaire-based on Mental and } \\
\text { conceptualmodel }\end{array}$ \\
\hline (Alshammari et al., 2015) & Adaptive E-Learning systems & $\begin{array}{l}\text { Usability evaluation of adaptive and } \\
\text { non-adaptive E-learning systems }\end{array}$ \\
\hline (Gordillo et al., 2015) & E-learning platform & $\begin{array}{l}\text { Interviews, Clickmaps and } \\
\text { Scrolmaps }\end{array}$ \\
\hline (Revythi \& Tselios, 2019) & LMS in Africa & Heuristic Usability \\
\hline
\end{tabular}

\section{Methods and Materials}

Following Figure. 1 shows the research methodology of this paper. In this study, the first evaluation methods were selected. Then evaluation was conducted via 15 participants of user testing and 5 experts of Heuristic.

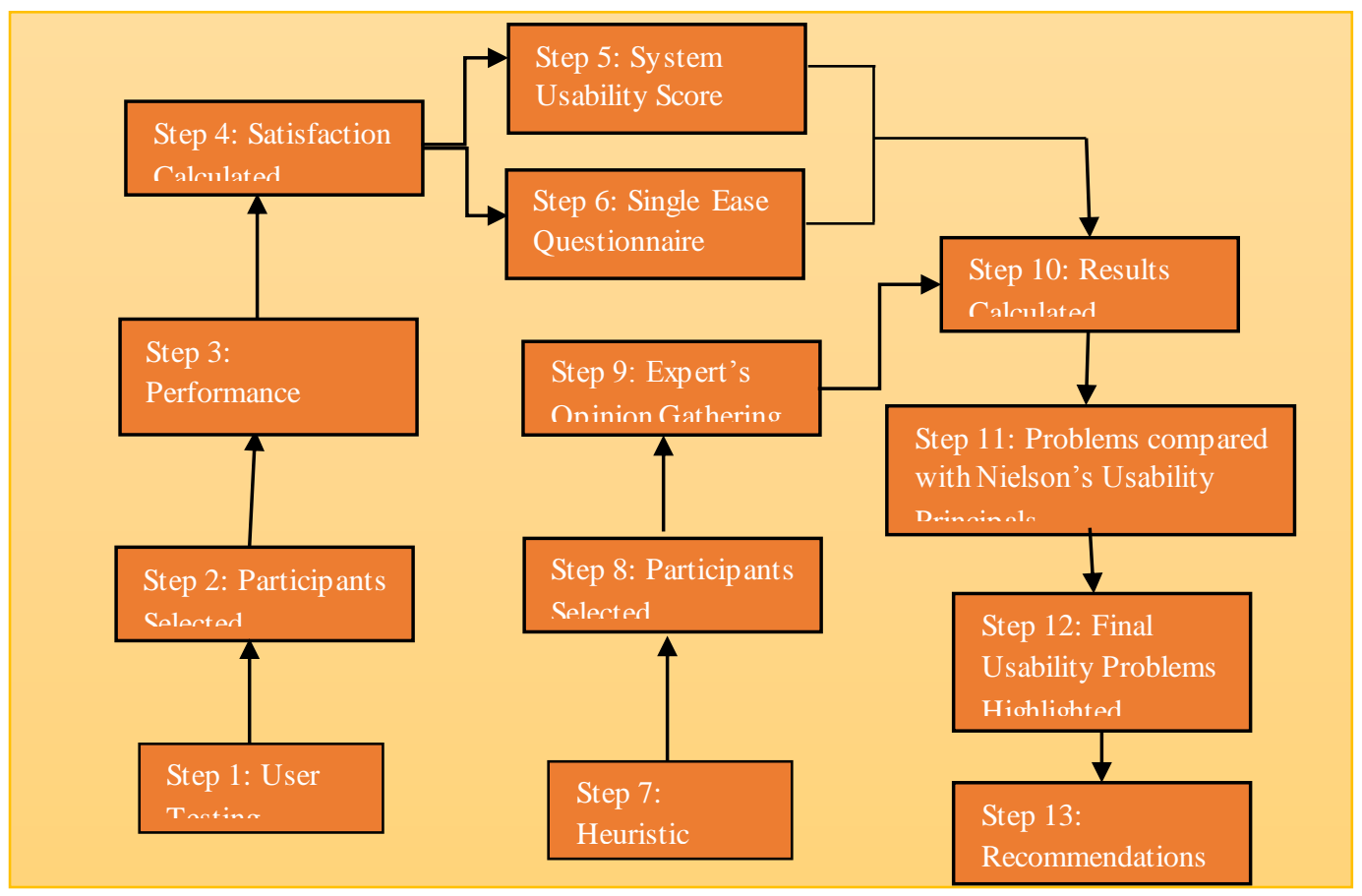


Figure 1: Detailed Steps of User Testing and Heuristic Evaluation

\section{User Testing}

Usability is a type of testing method which includes participants, tasks, and evaluators to measure performance time. This approach is adopted because, it already been used by many researchers for testing usability of learning management systems in (Granic, 2008) and (Gordillo et al., 2015)

This experiment is conducted among different types of users. Fifteen users participated in our experiment in total. All users were not of the same category. Their age and education standard varies as the website www.khanacademy.org belongs to online lectures for almost all kinds of learners. Five tasks were given to all users and their performance time was measured. They were free to use their choice of platform either desktop or mobile application. The majority of users used their mobile devices to accomplish the ir tasks. Time was measured while performing the tasks. Almost, all users completed all the tasks except the last task. People find difficulty in the last task (given below). Two users could not find out the answer to this task and left as incomplete. User's responses for interface were positive overall but, it was felt during an experiment that interface is unnecessary complex a little bit for initial educators like students of 9th standard. Then effectiveness, efficiency is calculated and satisfaction is calculated through the SUS Questionnaire scale. After completing the tasks, all users were given the System Usability Scale (SUS) Questionnaire. It is a questionnaire used to measure system-level performance. After the SUS score, we also compared our results with another task-level satisfaction that is Single Ease Questionnaire (SEQ). SEQ is designed for task satisfaction that contains only one question that is "How did you find this task?"

\section{Participants}

The task was conducted among 15 users in total. Among them, some were post-grad students and some were salary person. 10 users were selected for System Usability Scale (SUS) and 5 users participated in SEQ. All participants had known how of using the system and doing the task. All of them were given 5 tasks equally. Participants were free to use their choice of platform. Mostly, users used mobile devices. Whereas, some were easy to use desktop applications. Few of them were familiar with khanacademy.org and the rest of them were experienced in using different E-learning platforms.

\section{Tasks}

The steps followed:

- $\quad$ Login/Sign-up

- Select your education level. Select three courses "Grammar", "Algebra" and "Computer Science".

- $\quad$ Go to your profile and check for new badges/avatars.

- Go to the search option and search "What is Newton's first law".

- Go to your courses again. Open Algorithms, open Merge Sort, and email it to your colleague.

\section{Measure}

Refer to Table 2 below to learn the number of users who participated and check their performance time. Threshold time is set by taking an average of performance measure time. Values that are labeled below with Red color are rejected fields due to time's up. To calculate Effectiveness and Efficiency time required to perform the task was measured of every single user. Red-filled columns show that due to time running up these values were not considered while calculating usability metrics. To target usability metrics first, effectiveness and efficiency were calculated, and then satisfaction is being measured through two ways; system-level satisfaction and task level satisfaction. In this regard SUS (System level) and SEQ (Task level), satisfaction questionnaires are chosen for satisfaction evaluation.

Table 2: Performance time measured while users perform the tasks

\begin{tabular}{|c|c|c|c|c|c|}
\hline Users & Task 1 & Task 2 & Task 3 & Task 4 & Task 5 \\
\hline 1. & $138 \mathrm{sec}$ & $29 \mathrm{sec}$ & $10 \mathrm{sec}$ & $31 \mathrm{sec}$ & $115 \mathrm{sec}$ \\
\hline 2. & $60 \mathrm{sec}$ & $120 \mathrm{sec}$ & $120 \mathrm{sec}$ & $60 \mathrm{sec}$ & $120 \mathrm{sec}$ \\
\hline 3. & $33 \mathrm{sec}$ & $18 \mathrm{sec}$ & $30 \mathrm{sec}$ & $21 \mathrm{sec}$ & $180 \mathrm{sec}$ \\
\hline 4. & $34 \mathrm{sec}$ & $58 \mathrm{sec}$ & $15 \mathrm{sec}$ & $23 \mathrm{sec}$ & $51 \mathrm{sec}$ \\
\hline 5. & $95 \mathrm{sec}$ & $55 \mathrm{sec}$ & $28 \mathrm{sec}$ & $37 \mathrm{sec}$ & $97 \mathrm{sec}$ \\
\hline 6. & $30 \mathrm{sec}$ & $15 \mathrm{sec}$ & $20 \mathrm{sec}$ & $15 \mathrm{sec}$ & $45 \mathrm{sec}$ \\
\hline 7. & $50 \mathrm{sec}$ & $55 \mathrm{sec}$ & $45 \mathrm{sec}$ & $25 \mathrm{sec}$ & $80 \mathrm{sec}$ \\
\hline 8. & $120 \mathrm{sec}$ & $60 \mathrm{sec}$ & $120 \mathrm{sec}$ & $60 \mathrm{sec}$ & $120 \mathrm{sec}$ \\
\hline
\end{tabular}




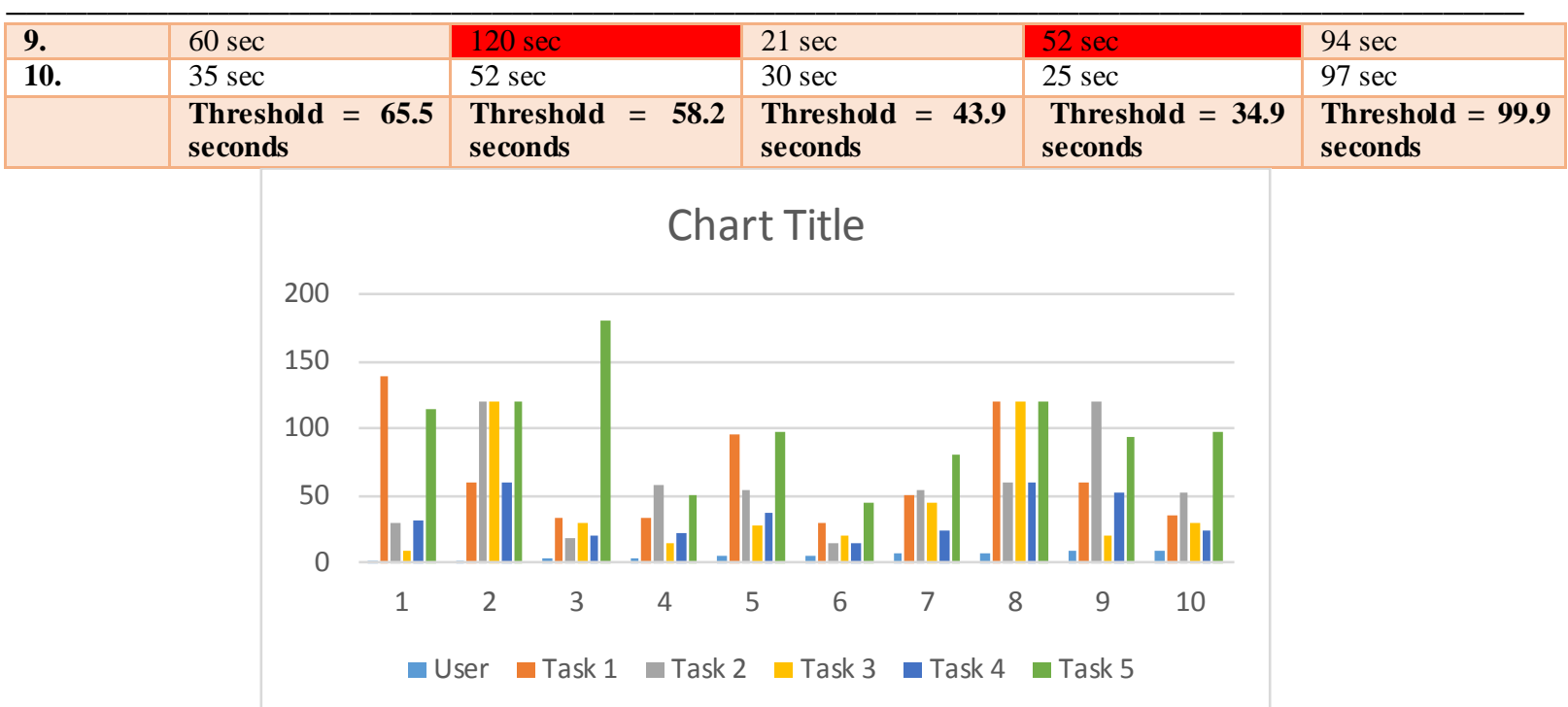

Figure 2: Representation of users taking time while performing tasks

Figure. 2 given shows the graphical representation of users taking time while performing tasks. The first bar of each user shows the number of the user. The rest of the 4 bars are representing the five tasks. Numbering (1-10) in horizontal shows the number of users. The number in vertical on the left-hand side of the figure from 0-200 shows the time taken by each user according to each task.

\section{Effectiveness}

Effectiveness is defined as the accuracy and completeness with which the user achieves specified goals.

Number of tasks completed successfully

$$
\mathrm{X} 100 \%
$$

Total number of tasks

Number of successful tasks $\div$ Total number of tasks ${ }^{*} 100$

$=\mathbf{3 4} \div 50$

$=0.68 * 100$

Effectiveness $=68 \%$

Efficiency

Efficiency is the accuracy and completeness with which users achieve specified goals.

$\overline{P_{t}}=\frac{\sum_{j-1}^{R} \sum_{i-1}^{N} \frac{n_{i j}}{t_{i j}}}{\mathrm{NR}}$

$\mathrm{n}_{\mathrm{ij}} \div \mathrm{t}_{\mathrm{ij}}$

Where;

$\mathrm{n}_{\mathrm{ij}}=$ Number of successes/failures. It is represented as 1 if successful and 0 if fails.

$\mathrm{t}_{\mathrm{ij}}=$ Time for successful task.

Efficiency $=2.18$ goals $/ 50$ seconds

\section{Satis faction through SUS}

SUS is an abbreviation of the System Usability Scale that is used to measure the satisfaction level of users regarding the interface of any website or application through a questionnaire. SUS method is adopted in this research following the footpath of (Ruipérez-Valiente, 2015). This questionnaire is given to users after using the system with some defined tasks. Then users provide their feedback through a questionnaire about their usage of the system. There are several Test-level Questionnaires. Most of them are licensed are quite costly. SUS is an open-source questionnaire and easy to calculate as well. SUS consists of 10 questions about the interface and usage of the system with a Likert scale (1-5). Below Table 3 shows the questionnaire. SUS is based on 10 questions that take users open feedback that how they felt about the interface. User after performing tasks provide their opinion by giving a rating (1-5) against each question of the survey. SUS is an effective way to validate the usability of the E-learning platform said by authors of (Alshammari et al., 
2015), (Kumar, 2017) and (Freire et al., 2012). Table 4 shows the SUS measurement for each question of every user. All the values of questions of a single user are added and multiply by 2.5 and the final answer is written in the last column of Table 4.

Table 3: System Usability Scale Questionnaire for Khan Academy

\begin{tabular}{|c|c|c|c|c|c|}
\hline Questions & 1 & 2 & 3 & 4 & 5 \\
\hline 1. I think that I would like to use this system frequently. & O & O & $\mathrm{O}$ & $\mathrm{O}$ & O \\
\hline 2. I found the systemunneces sarily complex. & O & $\mathrm{O}$ & $\mathrm{O}$ & $\mathrm{O}$ & $\mathrm{O}$ \\
\hline 3. I thought the systemwas easy to use. & O & $\mathrm{O}$ & $\mathrm{O}$ & $\mathrm{O}$ & $\mathrm{O}$ \\
\hline $\begin{array}{l}\text { 4. I think that I would need the support of a technical person } \\
\text { to be able to use the system. }\end{array}$ & $\mathrm{O}$ & D & ) & O & 7 \\
\hline $\begin{array}{l}\text { 5. I found the various functions in this system were well } \\
\text { integrated. }\end{array}$ & O & ) & ) & ) & D \\
\hline 6. I thought there was too much inconsistency in this system. & $\mathrm{O}$ & $\mathrm{O}$ & $\mathrm{O}$ & $\mathrm{O}$ & $\mathrm{O}$ \\
\hline $\begin{array}{l}\text { 7. I would imagine that most people would learn to use this } \\
\text { systemvery quickly. }\end{array}$ & & & & & \\
\hline 8. I found the systemvery cumbersome to use. & $\mathrm{O}$ & $\mathrm{O}$ & $\mathrm{O}$ & $\mathrm{O}$ & $\mathrm{O}$ \\
\hline 9. I felt very confident using this system. & $\mathrm{O}$ & $\mathrm{O}$ & $\mathrm{O}$ & $\mathrm{O}$ & $\mathrm{O}$ \\
\hline $\begin{array}{l}\text { 10. I needed to learn a lot of things before I could get going } \\
\text { with this system. }\end{array}$ & $\mathrm{O}$ & O & O & 0 & 0 \\
\hline
\end{tabular}

Table 4: Satisfaction calculated for each user according to SUS score.

\begin{tabular}{|c|c|c|c|c|c|c|c|c|c|c|c|}
\hline Users & $\begin{array}{l}\text { Quest } \\
\text { ion \# } \\
1\end{array}$ & $\begin{array}{l}\text { Quest } \\
\text { ion \# } \\
2\end{array}$ & $\begin{array}{c}\text { Quest } \\
\text { ion \# } \\
3\end{array}$ & $\begin{array}{l}\text { Quest } \\
\text { ion \# } \\
4\end{array}$ & $\begin{array}{l}\text { Quest } \\
\text { ion \# } \\
5\end{array}$ & $\begin{array}{l}\text { Quest } \\
\text { ion \# } \\
6\end{array}$ & $\begin{array}{l}\text { Quest } \\
\text { ion \# } \\
7\end{array}$ & $\begin{array}{l}\text { Quest } \\
\text { ion \# } \\
8\end{array}$ & $\begin{array}{c}\text { Quest } \\
\text { ion \# } \\
9\end{array}$ & $\begin{array}{c}\text { Quest } \\
\text { ion \# } \\
\mathbf{1 0}\end{array}$ & $\begin{array}{l}\text { Total Score } \\
\text { (Sum *2.5) }\end{array}$ \\
\hline 1. & 1 & 3 & 2 & 2 & 2 & 4 & 4 & 4 & 2 & 1 & 62.5 \\
\hline 2. & 2 & 4 & 4 & 4 & 2 & 3 & 1 & 4 & 3 & 4 & 77.5 \\
\hline 3. & 3 & 2 & 1 & 2 & 4 & 3 & 3 & 4 & 2 & 4 & 70 \\
\hline 4. & 2 & 4 & 3 & 2 & 2 & 1 & 1 & 2 & 2 & 3 & 55 \\
\hline 5. & 4 & 3 & 3 & 3 & 3 & 4 & 3 & 4 & 4 & 3 & 85 \\
\hline 6. & 4 & 3 & 2 & 3 & 4 & 4 & 3 & 4 & 4 & 1 & 80 \\
\hline 7. & 4 & 3 & 4 & 3 & 3 & 3 & 2 & 4 & 3 & 3 & 80 \\
\hline 8. & 3 & 2 & 4 & 4 & 2 & 3 & 3 & 4 & 3 & 4 & 80 \\
\hline 9. & 2 & 3 & 4 & 3 & 2 & 2 & 3 & 3 & 3 & 4 & 72.5 \\
\hline 10. & 1 & 3 & 1 & 2 & 4 & 3 & 1 & 2 & 3 & 1 & 52.5 \\
\hline & & & & & & & & & & & Total $=715$ \\
\hline
\end{tabular}

Average $=715 \div 10$

SUS score $=71.5$ (Acceptable)

It is believed that if the mean is above 67 then the website/interface is acceptable.

\section{Satis faction through SEQ}

Single Ease Questionnaire is another kind of satisfaction questionnaire but it is taken from users regarding tasks instead of the whole system. As SUS Score is known for system-level satisfaction, similarly, SEQ is named for task-level satisfaction. SEQ contains only one question that is "How did you find this task". SEQ is given to participated users and they provide feedback through these questions regarding tasks. This single question is based on a 7 Likert scale (1-7). There are although, many other task level and system level questionnaires are designed these two Questionnaires a re easy approaches and proved ones and they have been used in many types of research.

Task-level satisfaction is measured by calculating these scale values. The scale given below indicates the ratings (1-7) that tell; Very Difficult, Difficult, Somehow Difficult, Neutral, Somehow Easy, Easy, and Very easy as shown in figure 3.

\begin{tabular}{ll|l|l|l|l}
\hline & 2 & 3 & 1 & 1 & 7
\end{tabular}

\section{Figure 3: SEQ Rating Scale}

The above-given severity ratings indicate the condition of each task for users to help them while filling up the questionnaire.

The answers given for each task are given in Table 5 by users according to the rate of scale. 


\begin{tabular}{|c|l|l|l|l|l|}
\hline \multicolumn{7}{|c|}{ Table 5: Ratings given by participants for all tasks } & & \\
\hline Sr. \# & Task 1 & Task 2 & Task 3 & Task 4 & Task 5 \\
\hline 1. & 6 & 7 & 4 & 6 & 5 \\
\hline 2. & 7 & 3 & 5 & 7 & 3 \\
\hline 3. & 6 & 3 & 7 & 7 & 6 \\
\hline 4. & 4 & 7 & 5 & 6 & 4 \\
\hline 5. & 7 & 6 & 5 & 7 & \\
\hline
\end{tabular}

\section{Calculation Method}

Several users multiple by cell number of scale divide by a total number of users. This method is performed for every single task. Then, the average ratio is calculated against each task. In the end, all the answers for each task are summed up and divide by a total number of users. The final answer is matched with the cell number of the Likert scale. The closest cell is indicated as the final answer.

Consider the calculation for the values of above table 5 for better understanding.

\section{Calculation}

Task 1:

$2 * 6+2 * 7+1 * 4$

$=30 / 5$

$=6($ Easy $)$

Task 2:

$2 * 7+2 * 3+1 * 6$

$=26 / 5$

$=5.2$ (Somehow, Easy)

Task 3:

$3 * 5+1 * 4+1 * 7$

$=26 / 5$

$=5.2$ (Somehow, Easy)

Task 4:

$2 * 6+3 * 7$

$=33 / 5$

$=6.6$ (Very Easy)

Task 5:

$1 * 5+1 * 3+1 * 1+1 * 6+1 * 4$

$=19 / 5$

$=3.8$ (Neutral)

Total $=6+5.2+5.2+6.6+3.8$

$=5.36$ (Somehow, Easy).

\section{He uristic Evaluation}

Heuristic evaluation is one type of inspection method. Jakob Nielsen and Molich defined 10 usability principles in 1990 (Ruipérez-valiente et al., 2015). Developers should consider these standards while designing the interface of the E-learning program. These principles are helpful for UI/UX designers as well as for developers. These 10 standards are first explained to evaluators so they could have a better understanding of examining the interface of khan Academy. 10 heuristics are described well in Table 6 defining each heuristic with an explanation.

Table 6: Nielsen's 10 Usability Heuristics with Explanation

\begin{tabular}{ll}
\hline Sr.\# & Niels en's Heuristics \\
\hline 1. & Visibility of System Status: \\
& The users should know what is happening on the system through appropriate feedback. It makes the \\
& users more confident and encourages themto carry on.
\end{tabular}

\section{Match between System and the Real Word:}

The interface should use simple words, phrases, and understandable language for novice and experienced users. The users should easily understand the system message, furthermore; objects and functions presented by the systems hould be clear and easy to understand.

3. User Control and Freedom:

The system should resist students from input errors. It distinguishes between cognitive errors and input errors. The users feel independent while using the system for example; they can save the profile in any state. 


\section{Consistency and Standards:}

The users feel consistent while using the system. The interface follows the consistent universal standards in typography, color, and dialogue designs. The control keys should be consistent.

5. Error Prevention:

The E-learning platform should be designed that prevent students from making errors. These kinds of platforms should be designed in a way that gives another chance to a student in case wrong input is received by students.

6. Recognition rather than Recall:

Icons using in the interface of e-learning programs should be self-explanatory that don't make users memorize the relative function of a particular icon. They should follow consistent standards.

7. Flexibility and Efficiency of Use:

An interface of LMS should be flexible for all kinds of users (novice/experienced). The interface should maintain its speed and provide a relative kind of flexibility to a particular type of user.

8. Aesthetic and Minimalist Design:

The design of the interface should be very simple and easy to understand. It should not contain any irrelevant information and everything on the interface is visible.

9.

Help Users Diagnose, Recognize and Recover from Errors:

E-learning programs should send an error message in a simple language that all kinds of students and learners should easily understand. It should suggest an appropriate way of solution as well.

10.

\section{Help and Documentation:}

The system should assist users when needed. Helping material should be in steps and simple language. There should be a proper module for help or may add an online chat option where users can easily ask for help.

There are many other researchers performed a Heuristic evaluation for different kind of Elearning programs for recommending to developers that how to build an E-learning platform and what principles must be followed while designing the interface.

Participants

Heuristic Evaluation is less expensive than other evaluation methods as it requires only 3-5 experts (Zhang et al., 2010). This study also contains 5 evaluators which 4 of them are IT specialist and one is a UI/UX designer. Concern Table 7 for demographic information of each evaluator.

Table 7: Demographic Information of Evaluators

\begin{tabular}{cllll}
\hline Sr.\# & Gender & Degree & Profession & Usage of E-learning websites \\
\hline 1. & Male & PhD & Sr. Assistant Professor & More than 8 years \\
2. & Male & MPHIL & Sr. Assistant Professor & More than 5 years \\
3. & Male & MPHIL & IT Officer & More than 5 years \\
4. & Male & PhD & Academic Officer (IT) & More than 4 years \\
5. & Male & BSIT (Hons) & UI/UX Designer & More than 5 years \\
\hline
\end{tabular}

Heuristic Analysis and Results

After taking demographic information of experts. They are asked to vis it khanacademy.org and complete the Questionnaire designed following the Heuristic standards. From that questionnaire cosmetic, minor and major errors are extracted. This study mainly focuses on major issues. The major issues arose in "Error Prevention" and "Aesthetic and Minimalist Design". This means this website does not prevent users from making errors and users don't get properly informed in the state of error. For example; one evaluator stated that "I get difficulty even finding error message for invalid sign-in". Another expert commented that "Their way of showing messages is not very impressive". Further, an expert said; "They have used some jargon in some text and in some places to make a text line short, they have made it difficult for some users to understand". Evaluators also complained about the sound alert for the error message. One stated; "In my opinion sound alert should be there in many cases". Other major issues are found in Aesthetic and Minimalist Design. As evaluators found difficulty in changing the language of the website. For instance, an evaluator mentioned that "Yes, it is there down on the page but difficult to find easily". An expert added into this comment by saying "But in the case of Arabic, all the formatting is messed up and images disappear with all the animation". Regarding the same issue, another expert noted that "After sign in, when the page is up or open in mobile view, the title, of course, is fixed on top which is not necessary. Still, the new bar should be fixed if it is necessary to fix something". Recommendations have also been provided by evaluators for the improvement in interface. See Table 8 for the detailed result. 


\begin{tabular}{|c|c|c|c|c|}
\hline Sr.\# & Problem Type & Cosmetic & Minor & Major \\
\hline 1. & Visibility of System Status & 4 & 0 & 1 \\
\hline 2. & Match between System and Real World & 8 & 2 & 2 \\
\hline 3. & User Control and Freedom & 2 & 2 & 1 \\
\hline 4. & Consistency and Standards & 8 & 1 & 0 \\
\hline 5. & Error Prevention & 0 & 3 & 7 \\
\hline 6. & Recognition rather than Recall & 3 & 0 & 2 \\
\hline 7. & Flexibility and Efficiency of Use & 9 & 1 & 0 \\
\hline 8. & Aesthetic and Minimalist Design & 0 & 4 & 6 \\
\hline 9. & Help User Recognize, Diagnose and Recover from Errors & 8 & 0 & 2 \\
\hline 10. & Help and Documentation & 3 & 2 & 0 \\
\hline
\end{tabular}

\section{Recommendations}

- $\quad$ For more visibility, it is suggested that a button should be present to adjust the variable font size of the content. It will be helpful for learners who use eyesight glasses. Also, pop-up windows should be designed in a more unique way that could make them extra visible.

- $\quad$ To provide more flexibility to users, it is recommended that Khan Academy should not use jargon in messages to provide clear and understandable helping messages.

- To provide more control, every page should have a "next/present" indicator button. Also, for more freedom, an undo function should exist all the time on the interface.

- $\quad$ To maintain consistency, the navigation bar should be fixed.

- To prevent users from errors, it is suggested that to add a sound alert to inform users when an error occurs and show an appropriate error message.

- $\quad$ For efficiency of using Khan Academy, it is indorsed to provide a visible option of changing the language on the main page. For instance, on top right or some other more suitable era. Also, for students of kindergarten to 7th standard, an expert recommended that an interface should be different with changed graphics. There could be an option to change the theme of the interface for children or something like that.

- To help users, recognize, diagnose and recover from the error, provide error messages with better use of graphics to help messages to become more prominent.

\section{Possible Solutions}

Let's see Table 9 to find the suggested Improvement against each problem type.

Table 9: Recommendation against Heuristic Problem

\begin{tabular}{|c|c|c|}
\hline Sr.\# & Heuristic Type & Suggested Improvement \\
\hline 1. & Visibility of System Status & $\begin{array}{l}\text { For more visibility, it is suggested that a button should be } \\
\text { present to adjust the variable font size of the content. It will be } \\
\text { helpful for learners who use eyesight glasses. Also, pop-up } \\
\text { windows should be designed in a more unique way that could } \\
\text { make them extra visible. }\end{array}$ \\
\hline 2. & $\begin{array}{l}\text { Match Between System and } \\
\text { Real World }\end{array}$ & $\begin{array}{l}\text { To provide more flexibility to users, it is recommended that } \\
\text { KhanAcademy should not use jargon in messages to provide } \\
\text { clear and understandable helping messages. }\end{array}$ \\
\hline 3. & User Control and Freedom & $\begin{array}{l}\text { To provide more control, every page should have a } \\
\text { "next/present" indicator button. Also, for more freedom, an } \\
\text { undo function should exist all the time on the interface. }\end{array}$ \\
\hline 4. & Consistency and Standards & To maintain consistency, the navigation bar should be fixed. \\
\hline 5 . & Error Prevention & $\begin{array}{l}\text { To prevent users from errors, it is suggested that to add a sound } \\
\text { alert to inform users when an error occurs and show an } \\
\text { appropriate error message. }\end{array}$ \\
\hline 6. & $\begin{array}{l}\text { Aesthetic and } \\
\text { Design }\end{array}$ & $\begin{array}{l}\text { For efficiency of using KhanAcademy, it is indorsed to provide } \\
\text { a visible option of changing the language on the main page. For } \\
\text { instance, on top right or some other more suitable era. Also, for } \\
\text { students of kindergarten to } 7^{\text {th }} \text { standard, an expert recommended } \\
\text { that an interface should be different with changed graphics. } \\
\text { There could be an option to change the theme of the interface } \\
\text { for children or something like that. }\end{array}$ \\
\hline 7. & Recognize, & To help users, recognize, diagnose and recover from the error, \\
\hline
\end{tabular}




\begin{tabular}{ll}
$\begin{array}{l}\text { Diagnose and Recover from } \\
\text { Error }\end{array}$ & $\begin{array}{l}\text { provide error messages with better use of graphics to help } \\
\text { messages to become more prominent. }\end{array}$ \\
\hline
\end{tabular}

\section{Results and Discussion}

This section contains the discussion of results obtained from implementing two evaluations (usability testing and heuristic testing). The final result shows that Khan Academy is $68 \%$ effective and can efficiently perform 2.18 goals $/ 50$ seconds. Satisfaction score that is measured by two different ways stated that system-level satisfaction is $71.5 \%$ supposed by SUS scale and Task-level satisfaction scored 5.36 near to 5th cell number which indicates "Somehow, Easy" out of a scale of 7 ratings confirmed by SEQ scale. However, the Heuristic approach found major errors in "Error Prevention" and "Aesthetic and Minimalist Design". Furthermore, cosmetic and minor issues have been explained in Table 8. Recommendations provided against these issues have been agreed upon by 5 evaluators which specifies that amendments are required to make the Khan Academy more efficient and easy to use. During testing, it is observed that novice users had difficulty in performing the task as compared to experienced users. The experienced users also agreed that novice users may find tasks a difficult little bit. For instance, the last task "Go to your courses again. Open Algor ithms, open Merge Sort and email it to your colleague" was quite difficult for novice users. The majority of users performed this task taking 115-180 seconds whereas, two users failed to perform. Recommendations have been made by evaluators to remove these issues for all novice and experienced users. During this research, the importance of online platforms has been closely observed while the endangered spread of Coronavirus (Covid-19). Experts put their appeal to update the usability of the platform so that students could overcome their deficiencies in case of such unpredicted circumstances.

\section{Conclusion and Future Work}

In this paper, we have examined the usability of Khan Academy using two evaluation techniques. Usability testing is performed first with 15 participants. After calculating the effectiveness and efficiency of a website, satisfaction is measured using SUS and SEQ method. Many usability problems discovered by the heuristic approach are explained in heuristic results and analys is. Possible solutions encountered by evaluators are also recommended in Table 9. These results and recommendations are collected through a questionnaire based on 10 heuristic principles. One future work is possible to implement other usability techniques such as question-asking protocol or inquiry method to investigate the usability of KhanAcademy. While having the current conditions of Covid19 in mind, in the future, one can research taking suggestions of recent victims of institutes for improving e-learning platforms for better learning system.

\section{Acknowle dgment:}

The authors extend their appreciation to the Deanship of Scientific Research at King Khalid University, Saudi Arabia for funding this work under Research grant award number RGP. 1 / 370 / 42.

References

Al-Badi, A., Michelle, O., Al Roobaea, R., \& Mayhew, P. (2013). Improving Usability of Social Networking Systems: A Case Study of LinkedIn. Journal of Internet Social Networking and Virtual Communities, 2013, 1-23. https://doi.org/10.5171/2013.889433

Al-Dossari, H. (2017). A Heuristic Based Approach for Usability Evaluation of Academic Portals. International Journal of Computer Science and Information Technology, 9(3), 15-30. https://doi.org/10.5121/ijcsit.2017.9302

Al-khalifa, H. S. (2010). A First Step in Evaluating the Usability of JUSUR Learning Management System. Paper Presented at The 3rd Annual Forum on E-Learning Excellence in the Middle East 2010: Bringing Global Quality to a Local Context. February 1st - 3rd, Dubai, U.A.E., August.

Alshammari, M., Anane, R., \& Hendley, R. J. (2015). Design and Usability Evaluation of Adaptive elearning. 1, 584-591. https://doi.org/10.1007/978-3-319-22668-2

Alsumait, A. (2009). Usability Heuristics Evaluation for Child E-learning. 425-430.

Aslam, M., Muhammad, S. S., Awan, S., \& Pervez, M. T. (2016). A TECHNIQUE TO INCREASE THE USABILITY OF E-LEARNING WEBSITES. July.

Debevc, P. M. (2000). Usability testing of e-learning content as used in two learning management systems. 1-8.

Ertürk, A., \& Önaçan, M. B. K. (2016). Usability Evaluation of Learning Management System in a Higher Education Institution: a Scale Development Study. Journal of Global Strategic Management, 2(10), 73-73. https://doi.org/10.20460/jgsm.20161024357 
Freire, L. L., Arezes, P. M., \& Campos, J. C. (2012). A literature review about usability evaluation methods for e-learning platforms. Work, 41(SUPPL.1), 1038-1044. https://doi.org/10.3233/ WOR-2012-0281-1038

Gordillo, A., Barra, E., Aguirre, S., \& Quemada, J. (2015). The usefulness of usability and user experience evaluation methods on an e-Learning platform development from a developer's perspective: A case study. Proceedings - Frontiers in Education Conference, FIE, 2015Febru(February). https://doi.org/10.1109/FIE.2014.7044340

Granic, A. (2008). Experience with usability evaluation of e-learning systems. 209-221. https://doi.org/10.1007/s10209-008-0118-z

Groth, A., \& Haslwanter, D. (2015). Efficiency, effectiveness, and satisfaction of responsive mobile tourism websites: a mobile usability study. Information Technology \& Tourism. https://doi.org/10.1007/s40558-015-0041-0

Holzinger, A. (2005). Usability engineering methods for software developers. Communications of the ACM , 48(1), 71-74. https://doi.org/10.1145/1039539.1039541

Jose, S. (2016). Usability and Effectiveness Evaluation of Adaptivity in E-Learning Systems. 29842991.

Katsanos, C., Tselios, N., \& Xenos, M. (2012). Perceived usability evaluation of learning management systems: The first step towards standardization of the system usability scale in Greek. Proceedings of the 2012 16th Panhellenic Conference on Informatics, PCI 2012, 302307. https://doi.org/10.1109/PCi.2012.38

Korableva, O., Durand, T., Kalimullina, O., \& Stepanova, I. (2019). Usability testing of MOOC: Identifying user interface problems. ICEIS 2019 - Proceedings of the 21st International Conference on Enterprise Information Systems, 2(Iceis), 468-475. https://doi.org/ $10.5220 / 0007800004680475$

Kumar, B. A. (2017). Usability of mobile learning applications : a systematic literature review. Journal of Computers in Education. https://doi.org/10.1007/s40692-017-0093-6

Lanzilotti, D. M. R. (2006). An approach to usability evaluation of e-learning applications. 270-283. https://doi.org/10.1007/s10209-005-0008-6

Mkpojiogu, E. O. C., Hussain, A., \& Hassan, F. (2018). A systematic review of usability quality attributes for the evaluation of mobile learning applications for children. AIP Conference Proceedings, 2016. https://doi.org/10.1063/1.5055494

Mtebe, J. S., \& Kissaka, M. M. (2015). Heuristics for evaluating the usability of Learning Management Systems in Africa. 2015 IST-Africa Conference, IST-Africa 2015, 1-13. https://doi.org/10.1109/ISTAFRICA.2015.7190521

Revythi, A., \& Tselios, N. (2019). Extension of technology acceptance model by using system usability scale to assess behavioral intention to use e-learning. Education and Information Technologies, 24(4), 2341-2355. https://doi.org/10.1007/s10639-019-09869-4

Ruipérez-valiente, J. A., Muñoz-merino, P. J., Leony, D., \& Delgado, C. (2015). Computers in Human Behavior ALAS-KA: A learning analytics extension for better understanding the learning process in the Khan Academy platform. 47, 139-148. https://doi.org/ 10.1016/j.chb.2014.07.002

Thielsch, M. T., Blotenberg, I., \& Jaron, R. (2014). User evaluation of websites: From the first impression to a recommendation. Interacting with Computers, 26(1), 89-102. https://doi.org/10.1093/iwc/iwt033

Zhang, T., Rau, P. P., \& Salvendy, G. (2010). Exploring critical usability factors for handsets. 29(1), 45-55. https $/ /$ doi.org/10.1080/01449290802666747 